\title{
REALIDADE E IMAGINÁRIO NO PROCESSO DE VIVER DE MORADORES EM UM DISTRITO BRASILEIRO ${ }^{1}$ \\ REALITY AND IMAGINATION IN THE PROCESS OF LIVING OF HABITANTS IN A \\ BRAZILIAN DISTRICT \\ REALIDAD E IMAGINARIO EN EL PROCESO DE VIVIR DE LOS HABITANTES DE UN DISTRITO BRASILEÑO
}

\author{
Claudia Maria de Mattos Penna²
}

${ }^{1}$ Extraído do relatório de Pós-doutorado sob orientação de Michel Maffesoli da Academie de Paris Sorbonne, na Université René Descartes, Paris V - U.E.R Sciences Sociales, Centre D’Étude sur L'Actuel et Le Quotidien. Bolsa Capes 2005/2006.

${ }^{2}$ Doutora em Filosofia de Enfermagem. Professora Adjunto na Escola de Enfermagem da Universidade Federal de Minas Gerais (UFMG).

PALAVRAS-CHAVE: Qualidade de vida. Meio ambiente e saúde pública. Direito à saúde. Condições sociais.

KEYWORDS: Quality of life. Environment andpublichealth Righttohealth.Socialconditions.

PALABRAS CLAVE: Calidad devida. Medio ambienteysalud pública. Derecho a la salud. Condiciones sociales.
RESUMO: O presente artigo é um estudo de caso qualitativo realizado com moradores de um distrito do Estado de Minas Gerais, com o objetivo de compreender as relações estabelecidas pelos moradores com o espaço onde vivem, que é região endêmica para esquistossomose. Utilizou-se entrevista para a coleta de dados. A análise mostra que os moradores têm conhecimento dos problemas causados pela existência da esquistossomose na região, delineando a realidade em que sobrevivem. Esta, entretanto, é relativizada pelo imaginário de que a água que possuem é boa, pois nesse espaço constroem seu processo de viver mesmo que em condições precárias. A vida dessas pessoas é vivida da forma que elas concebem, apesar das contradições que possam ser observadas, elas sempre buscam melhorias para a qualidade de vida do lugar e de si próprios.

ABSTRACT: This article is a qualitative case study developed in a rural district of Minas Gerais, Brazil. The objective of this study is to understand the relationships established among inhabitants and the arena in which they live, specifically a locale endemic for schistosomiasis. The data was collected by means of interviews. The results show that individuals are aware of the problems caused by the infection, outlining the reality in which they survive. However, this is related to their imaginary reality that the water each personally uses is good; and it is in this arena they construct their respective processes of living within such precarious conditions. The life of these individuals is conducted according to their own conception of living. Although significant contradictions can be observed, they continuously search for improvements in their quality of life, the environment, and themselves.

RESUMEN: Se trata de un estudio cualitativo realizado con residentes de un distrito del estado de Minas Gerais, caracterizado como siendo una región endémica de esquistosomiasis. El objetivo de este estudio fue comprender las relaciones establecidas por esas personas en el espacio donde viven. Fue utilizada una técnica de entrevista para la recolección de los datos. El análisis muestra que las personas estudiadas tienen conocimientos de los problemas causados por la existencia de esquistosomiasis en la región, diseñando la realidad en donde sobreviven. Ésta, sin embargo, es relativizada por el imaginario de que el agua que poseen es de buena calidad, pues en ese espacio construyeron su proceso de vivir aun cuando las condiciones son precarias. La vida de esas personas es vivida de la forma como la conciben, a pesar de las contradicciones que puedan ser observadas, ellos siempre buscan mejorías para la cualidad de vida del lugar y de sí propios.
Endereço: Claudia Maria de Mattos Penna

R. Paulo Piedade Campos, 664, Ap. 203

30.455-250 - Belo Horizonte, MG.

E-mail: cmpenna@enf.ufmg.br
Artigo original: Pesquisa

Recebido em: 10 de agosto de 2006. Aprovação final: 27 de dezembro de 2006. 


\section{PRETEXTO}

Os estudos atuais que enfocam a questão da saúde e doença das pessoas mostram que o processo de ser saudável e de adoecimento estão relacionados com as questões sócio-culturais, ambientais, além das biológicas e das interações estabelecidas com o espaço onde vivem. Daí a necessidade de compreender o cotidiano das pessoas, como elas o vivenciam e enfrentam as adversidades que se apresentam em seu dia a dia na construção de seu processo de viver.

O presente trabalho faz parte de um estudo ampliado, que teve por finalidade aprofundar um olhar sócio-antropológico sobre o cotidiano dos moradores de uma região endêmica para esquistossomose. Buscouse um olhar compreensivo natentativade compreender a relação que as pessoas mantêm com o espaço onde moram, como estabelecem sua vida cotidiana, seu processo de viver a partir de suas experiências de vida neste lugar. Sabe-se que estudos epidemiológicos aliados aos sócio-antropológicos vêm se expandido entre os pesquisadores das questões de saúde. Quando se trata de doenças endêmicas, por exemplo, a epidemiologia vem avançando sobremaneira no conhecimento clínico, imunológico e terapêutico como no caso da esquistossomose. Se, por um lado, os resultados desses estudos estabelecem os programas de controle governamentais sobre a doença, buscando relacionar os determinantes sócio-culturais, sob um olhar objetivo, por outro lado, as necessidades e os significados que as pessoas atribuem ao seu adoecimento não podem ser ignorados. Pois a forma como as pessoas vivenciam seu cotidiano, mostra um querer viver que vai além de possíveis normas ou regras de condutas estabelecidas e que influencia no controle de qualquer doença.

Este estudo foi realizado junto a uma comunidade que se localiza no Vale do Jequitinhonha, região nordeste de Minas Gerais. O Vale é assim chamado devido ao rio de mesmo nome, que tem sua nascente e maior extensão no Estado, e segue em direção ao Estado da Bahia, para desaguar no Oceano Attântico. NalínguaindígenaJequitinhonhasignifica riolargo que tem peixe, o que nos indica uma das funções desse rio e sua importância para as populações que habitam sua margem, o fornecimento de alimentação.

Em suas margens situam-se várias cidades, centenárias, constituídas por desbravadores paulistas e baianos, no século XVII, que buscavam ouro e diamantes no leito do rio. A maioria dessas cidades tem nome de origem indígena, herança dos povos que habitavam a região antes da chegada dos desbravadores.
Portanto, outra função do rio é povoar o imaginário das pessoas em busca do sonho de enriquecimento através da extração de diamantes, que ocorre na região há três séculos, o que tem causado problemas no leito do rio, principalmente depois que empresas passaram a utilizar dragas para a extração, provocando impactos mais depredadores do meio ambiente do que aqueles provocados pelos garimpeiros. ${ }^{1}$

A região apresenta contrastes incríveis. A paisagem admirável e indescritível, que se desvenda aos olhos, é moldada por montanhas que circundam o rio Jequitinhonha e o acompanham ao longo de seu curso. Possui um clima quente com médias anuais de $24^{\circ} \mathrm{C}$, com dois períodos distintos um de chuva e outro de seca. Porém, o desmatamento provocado ao longo dos anos advindos da mineração e das atividades de agro-pecuárias, provocou sérios problemas tanto na vegetação como no leito do rio. Houve períodos de seca que diminuiu consideravelmente seu volume, em contrapartida as enchentes já provocaram catástrofes nas cidades circunvizinhas. Da mesma forma que, "o índice de pobreza ostentado pela região é elevado, ocasionando êxodo rural para os grandes centros urbanos eum esvaziamento demográfico persistente. Com mais de dois terços da população vivendo na zona rural, ela tem sido caracterizada em vários estudos como 'região deprimida', onde osíndices de pobreza, miséria, desnutrição, mortalidade, analfabetismo, desempregoe infraestruturasócio-econômicaimperamdesfavoravelmente em grande parte dos municípios" 2:10

Consequentemente o quadro da saúde também é desfavorável. Ali se confundem doenças infecto-contagiosas com as cardiovasculares. O saneamento básico na região é precário, sendo que o abastecimento de água encanada e tratada é parcial; a rede de esgoto em sua grande maioria é a céu aberto, favorecendo a contaminação da água e consequentemente o aparecimento de doenças; o destino do lixo não é o mais recomendável, sendo que em alguns lugares o despejo se dá nos rios ou córregos próximos.Éevidente queháuma relação direta entre o nível de saúde e a qualidade dos serviços a que a população está exposta. A deterioração das condições de vida e as péssimas condições de saneamento têm favorecido a persistência de elevados coeficientes de algumas doenças de veiculação hídrica, principalmentea esquistossomose, bemcomo o reaparecimentodeoutras, como a cólera. A má qualidade da água disponível para o abastecimento, o esgotamento sanitário e a disposição dos resíduos sólidosinfluenciam diretamente oíndice de mortalidade da população. Em 1988, segundo dados fornecidos pelo Cartório de Registro CivildeMinas Gerais, 
observava-se que as doenças infecciosas e parasitárias em geral ocupavam o segundo lugar entre as causas de mortalidade nos municípios da área, ficando as doenças do aparelho circulatório como a principal causadora de óbito da população. A baciado rio Jequitinhonha, região deelevado potencial natural edelocalização privilegiada, apresentamunicípioscombaixoníveldedesenvolvimento atrelado às condições sócio-econômicas. ${ }^{2}$

Entretanto, mesmo considerada uma das regiões mais pobres do país, o Vale do Jequitinhonha não se destaca somente por isso. Talvez pela necessidade de sobrevivência, talvez pelo fato de que a vida de todo dia não se fomenta apenas pelo sofrimento, mas também de outros sentimentos, o Vale é berço de artesões e músicos, verdadeiros artistas que mostram em suas obras a beleza e a riqueza do povo sofrido, mas também feliz. Oartesanatodesenvolvido revelauma herançaindígena e negra, já reconhecida mundialmente, sendo o ultimo traço dessas culturas na região, além das características físicas de seus habitantes.

É neste contexto, portanto, que se localiza a Comunidade de Caju, Município de Jequitinhonha, local onde moram os sujeitos do presente estudo. A escolha deste lugar se deve pelo fato do município ser locus de estudo, desde 2003, de um grupo de pesquisa multidisciplinarqueenvolve pesquisadores do Centrode PesquisasRenéRachou,FundaçãoOswaldoCruz(FIOCRUZ),University of New York atBuffalo, University of Califórnia, San Francisco e Universidade Federal de Minas Gerais (UFMG). O grupo desenvolve estudos na área de helmintoses em região endêmica no Estado de Minas Gerais sobre fatores imunológicos, genéticos, ambientais e comportamentais envolvidos na aquisição dessas parasitoses, entre elas a esquistossomose.

Se de um lado, medidas de higiene e saneamento básico podem facilmente controlar a esquistossomose; de outro lado, ela ainda se constitui em um problema relevante para a saúde pública, pelo número de pessoas infectadas, em torno de 200 milhões em todo o mundo, sendo que no Brasil encontram-se seis milhões de infectados.

É inegável que os comportamentos das pessoas são influenciados pelas relações sócio-culturais que estabelecem em seu viver cotidiano, como também com aquelas que estabelecem com o espaço onde estão inseridos. Este, entendido aqui, como o "espaço vivido em comum onde circulam as emoções, os afetos e os símbolos, o espaço onde se inscreve a memória coletiva, o espaço enfim que permite a identificação" 3:229 dos moradores de uma região.
A importância a ser dada, neste estudo, para o espaço é o fato de a esquistossomose ser "uma doença de veiculação hídrica, diretamente ligada às condições de saneamento e à maneira de viver das populações situadas em áreas endêmicas". 3:81 Então, há de se considerar como o homem relaciona-se com o lugar onde mora, onde co-habita com os outros. Este que é "o espaço onde nós vivemos, no qual nossa existência 'explode' nas suas mais variadas manifestações. Que nós percorremos e dominamos com formas, linhas. O espaço de nosso corpo, de nosso 'Eros', o espaço da violência e do trabalho. Da guerra e do sagrado... Espaço onde se realizam as trocas e pelo qual somente as coisas adquirem isto que chamamos de 'valor'... Espaços onde se jogam os sonhos". 4:123

Portanto, estudou-se esse micro-espaço, as micro-relações, não em detrimento às macro-estruturas, mas buscando compreendê-lo no processo de vida das pessoas. Entender a vida cotidiana onde o homem se situa, construindo suas experiências, vivenciando suas preocupações e angústias, suas alegrias e tristezas, sua saúde e sua doença, em uma relação face a face com o outro, nesse espaço - tempo presente culturalmente determinado. Porque é nesse presente que se estabelece o processo de viver humano, no qual o homem nasce, cresce, aprende e ensina, trabalha e mantém relações sociais, é saudável e adoece, cuida e é cuidado, envelhece e morre. Centrar o estudo nas questões do cotidiano, como um lócus privilegiado onde ocorrem as mais diversas interações humanas. Pois, "a existência corrente, a vida sem qualidade, através de seus momentos os mais insignificantes, de suas situações sem grande importância, advém uma perpétua criação, mesmo e, sobretudo, se ela não se projeta em um ideal longínquo, mas se vive no presente em um lugar que eu divido com os outros". 5:46

Assim, o presente estudo teve por objetivo compreender as relações estabelecidas pelos habitantes com o espaço onde vivem, principalmente com a água, por ser uma região endêmica para esquistossomose. Ao buscar a compreensão do processo de viver das pessoas em sua vida cotidiana, é necessário considerar a forma fragmentada e plural como ela se mostra, desvelando um lado de sombras, caótico, banal, que geralmente é desprezado pela abordagem positivista, mas que não deixa de ter significado para o sujeito.

\section{O TRAJETO METODOLÓGICO}

Para alcance do objetivo proposto foi realizado um estudo de caso de natureza qualitativa. Estabeleceu- 
se como fundamento teórico deste estudo a Sociologia Compreensiva, que consiste na busca de compreender o vivido de acordo com a experiência de quem o vive em um determinado tempo e espaço. Há, em toda atividade humana, uma carga emocional e afetiva, repleta de simbologia que constrói as experiências do homem. Estas experiências não podem ser interpretadas somente pelos meios racionais, meios que tentam explicar os fatos de forma lógica, aparando as arestas, sem considerar a subjetividade, o que deixa por vezes lacunas na descrição e compreensão dos fenômenos. ${ }^{6}$

O estudo de caso vem sendo utilizado de forma extensiva em pesquisas da área das ciências sociais, como estratégia adequada, quando se trata de fenômenos contemporâneos inseridos em contextos da vida real e podem ser complementados por outras investigações de caráter exploratório e descritivo.?

Os respondentes foram moradores de Caju, na maioria mulheres, com idade superior a 18 anos. Esta localidade está distante $40 \mathrm{~km}$ da zona urbana por estrada não pavimentada, de difícil acesso durante a época de chuvas. O distrito de Caju possui população de cerca de 400 habitantes, além de 200 outros indivíduos que habitam aglomerados de casas à beira de córregos e seus afluentes, localizados em média entre três a oito quilômetros de distância da vila. $\mathrm{O}$ vilarejo possui Escola de $1^{\circ}$ grau, um Centro de Saúde com uma auxiliar de enfermagem que faz atendimento de pequenas urgências como curativos, além da distribuição de medicamentos hipotensores, antipiréticos e analgésicos. É importante ressaltar que nem sempre há disponibilidade de medicamentos e materiais para curativos no Centro. A assistência médica é feita na região urbana do município e o transporte é por ônibus ou nos casos mais graves por uma única ambulância que serve a região e que nem sempre está disponível. Em geral, os moradores recorrem, primeiramente, a benzedeiras ou tratam da doença em casa com chás. Somente em casos de extrema necessidade procuram o serviço médico em Jequitinhonha pelo fato da distância e o transporte caro e difícil.

Os sujeitos foram entrevistados em suas residências, em horário pré-determinado por eles, a partir de um roteiro básico de perguntas sobre saúde e doença e a relação com o espaço onde vivem. Foram gravadas, com permissão prévia, para garantir a confiabilidade das informações. Eles foram informados dos objetivos da pesquisa, assinaram Termo de Consentimento Livre e Esclarecido, assegurando-se dos direitos devidos enquantoinformantes, taiscomo, anonimato, confiabilidade das respostas e a possibilidade de se retirar do estudo aqualquer momento, sem nenhum ônus, de acordo com a Resolução 196/96 do Conselho Nacional de Pesquisa. Antes de iniciar a coleta de dados, o projeto de pesquisa foi avaliado e aprovado pelo Comitêde Ética em Pesquisa da Universidade Federal de Minas Gerais de acordo com o protocolo de número 0165.0203.000-05.

Após a transcrição das fitas foram feitas leituras dos relatos com o objetivo de encontrar unidades de significados, que foram organizados em temas, interpretados e discutidos com a literatura.

\section{ÁGUA, ESPAÇO E SAÚDE: DIREITO, RE- ALIDADE E IMAGINÁRIO}

O Distrito de Caju possui clima semi-árido, cuja principal atividade econômica dos habitantes é basicamente plantação de mandioca, milho e feijão além de criação de gado. O trabalho de lavoura é executado tanto por homens quanto por mulheres e crianças. Algunsindivíduos possuem negócio próprio principalmente relacionado a pequeno comércio e produção de cachaça. As casas de Caju são, em geral, construções simples e possuem luz elétrica. Não existe sistema de abastecimento de água tratada e rede de esgoto. Algumas casas possuem fossa seca e água encanada proveniente de nascentes ou cisternas. Outras não possuem nem uma fonte de água no domicílio e por isso utilizam o abastecimento de água da comunidade (chafariz comunitário) ou a água da cisterna de vizinhos. Portanto, a ausência de água encanada nos domicíliosfaz com que os moradores tenham contato com os córregos em suas atividades mais habituais, como as de lavar vasilhas ou roupas, no caso das mulheres e nos trabalhos de pecuária e agricultura exercidos pelos homens.

Ele [marido] tem contato com a água do córrego, com qualquer água, porque tanto ele trabalha na roça como épedreiro (e1); [...] e o contato do córrego sempre a gente tem, às vezes a água falta em casa, a gente tem que limpar, lavar as vasilhas, roupa do mesmo jeito. Se a água faltou a gente vai ao córrego lavar roupa. Ela vem no cano, mas continua sendo aquela mesma água do córrego que a gente pega lá (e7).

O problema que se apresenta é que a prevalência de esquistossomose na comunidade é de mais de 60\%. A constatação de que a contaminação geralmente se dá nas proximidades das moradias já foi mostrado em vários estudos, isto não é uma novidade em se tratando dessa parasitose. Reafirma-se que o saneamento básico, com odevido tratamento daágua, seja a melhor prevenção para evitar a contaminação. Além disso, há décadas que os programas de educação em saúde apregoam que mudança no estilo de vida das pessoas é a maior arma 
para combater as doenças de modo geral. Por conseguinte, as pessoas se contaminam porque não mudam seus comportamentos e o ciclo vicioso continua.

Entretanto, essaé a lógica positivista que permeia o cuidado em saúde e prevê a "docilidade" dos corpos que se submetem e se disciplinam às normas estabelecidas pelas políticas públicas. Pois, "é dócil um corpo que pode se submeter, pode ser utilizado, transformado e aperfeiçoado. A escala do controle: não é tratar o corpo por atacado, como se fosse uma unidade indissociável, mas de trabalhá-lo no detalhe; de exercer sobre ele uma coerção tênue, assegurar capturas ao nível mesmo mecânico - movimentos, gestos, atitudes, rapidez: poder infinitesimal sobre o corpo ativo. A modalidade enfim: implica uma coerção ininterrupta, constante, que vela sobre os processos da atividade mais que seu resultado e ela se exerce de acordo com uma codificação que enquadra, bem perto, o tempo, o espaço e o movimento. "Esses métodos que permitem o controle minucioso das operações dos corpos, que ajustam constantemente suas forças e lhes impõem uma relação de docilidade - utilidade, isto é o que pode-se chamar de 'disciplinas'. A disciplina fabrica assim os corpos submissos e treinados, os corpos 'dóceis"”. 8:509-10

Entretanto, há de se ressaltar que, a vida cotidiana não é só razão, deve se juntar a ela a paixão, o jogo dos afetos, a imprevisibilidade dos momentos compartilhados, além do lúdico, das brincadeiras, os "pequenos nadas" que a constroem, os pequenos prazeres. ${ }^{10 .}$ Os "dóceis corpos" não se submetem tanto às regras impostas.

Nadar no córrego. É animado (e8).

É bom demais plantar na beira do córrego, só que en não molho com a água do córrego não, eu molho com a água da mangueira por que a água do córrego está podre, é esgoto que cai aí. Ai eu não molbo com a água do córrego eu molho com a água da mangueira (e1).

A consciência de que, ao manterem contato com a água do córrego ou das nascentes, podem se contaminar com a esquistossomose, parece não fazer parte do dia a dia das preocupações dos moradores, pois o viver cotidiano vai além das prescrições sobre as formas de evitar a doença. É evidente para alguns respondentes certa descrença de que a água da região seja de fato contaminada.

Nadava no córrego aqui na fazenda que meu pai morava a gente brincava muito na água, o pessoal falava, e lá tinha esse caramijo na água... Mas não sabia da história da "xistosomose". Depois que comecei estudar, falavam, mas eu não levava aquilo a sério. Tem caramujo, mas ele está lá, sabia que ele transmitia a
"Xistosomose", via contar umas histórias iguais essas estudadas, sabia, não levava a sério muito, tomava banho. Eu não posso falar que eu adquiri a xistosomose aqui né? Eu já tomava banho muito antes numa água que tinha caramujo (e6).

Igual aqui essa relação da água com a saúde, eles falam: "ah não, antigamente nunca teve esse negócio de morrer da água, isso o pessoal inventa, se a gente for preocupar com essas questões a gente acaba endoidando"... dar água fervida que não tem estação de tratamento ai quando a gente trabalha com as crianças isso na sala de aula e que às vezes a gente chega nas casas e presencia eles tomando água diretamente do córrego ou então da caixa e eles: "ah não, o que não mata engorda" (e10).

É necessário entender tal postura dos moradores, pois a preocupação excessiva sobre as questões da água regional ser ou não contaminada pela esquistossomose configura-se como algo não saudável, que não faz bem à saúde mental. É necessário imaginar que a água, elemento indispensável à existência humana, que está tão próxima, deveria ser boa. Pode-se afirmar que, "a cultura nos transmite as formas - várias vezes as palavras. Se nós soubermos reencontrar, apesar da cultura, um pouco de imaginação natural, um pouco de imaginação diante da natureza, nós compreenderemos que o simbolismoéuma potência material. Nossaimaginação pessoal transformaria naturalmente todos os símbolos hereditários porque os símbolos hereditários são de símbolos naturais. Uma vez mais, é necessário compreender que o sonho é uma força da natureza. Como nós teremos a ocasião de repetir, não se pode conhecer a pureza sem imaginá-la. Não se pode imaginá-la com força sem ver sua marca, sua prova, sua essência”. 10:155 A realidade que se apresenta pode não ser a melhor, mas existe aquilo que se ressalta como "[...] o valor inconsciente ligado a uma água pura". ${ }^{10: 153}$

Não é assim uma água bastante... a água tem uns meses que até seca, mas dá pra ter aquele cuidado de mudar a criação de uma manga para outra e vai levando a vida (e7).

Muito boa a água. Ela vem de debaixo da terra (e5).

Tais suposições se confrontam com a constatação de outra entrevistada que afirma: todo mundo sabe que o problema da água é seriíssimo aqui... temos água, não é de boa qualidade e, além disso, da água não ser de boa qualidade, a água não dá para demanda das pessoas, a água é pouca. Como nós agora visitamos algumas casas você viu que têm pessoas que ainda pegam água na casa da viz̨inha, não tem água em casa (e6).

Uma realidade difícil de entender para quem não convive com tais dificuldades. Acostumados à água que chega por torneiras, encanada, tal situação nem parece existir. Afinal, por ser um elemento de primeira necessidade, deveria ser um direito de qualquer pessoa. De 
fato, "melhor que qualquer outro, o homem do campo conhece o preço de uma água pura porque ele sabe que a pureza está em perigo, porque ele sabe também beber a água clara e fresca no bom momento, nos raros instantes onde o insípido tem um sabor, onde o ser inteiro deseja a água pura”. 10:159

É necessário reconhecer que as dificuldades são várias, nesse micro-espaço onde habitam. É necessário ressaltar que a água potável na atualidade tornou-se um problema mundial, conforme reafirmado noIV Fórum Mundial da Água ocorrido 2006, no México, de que o mundo está caminhando para uma grande crise da água que culminará no ano 2020. Considera-se ainda que da água existente no planeta, $97 \%$ são oceânicas, salgadas, $2 \%$ são de geleiras e, apenas $1 \%$ é doce, com condições de utilização. ${ }^{11}$ "Os problemas são rapidamente agravados em países tropicais, onde os custos do tratamento de águas poluídas têm compartilhado fundos com outras atividades mais urgentes. Entre essas atividades emergenciais constantes em países tropicais, destacam-se as doenças provocadas pela água não tratada, o que gera um ciclo de causa efeito de difícil solução". 12:372

Tais problemassão reafirmados pelos moradores, mesmo que não tenham conhecimento da gravidade mundial. É o micro-espaço cotidiano, que se mistura com o macro-espaço histórico e comprova o problema em que a água se constitui na atualidade e se reconhece "o problema da água".

Esses dias eu estive com o secretário de saúde. Ele me falou que está mandando o engenheiro aí para olhar a situação da água. Está vendo com a COPASA, para ver se tem a possibilidade da COPASA tomar conta da água daqui. Você sabe é um pouco complicado... você vê... é um lugarzinho pequeno. Eles vão ter que vir e como não vão ter um retorno financeiro mais ou menos bom eles não vão ter muito aquele interesse (e6).

Não tem essa preocupação e espera assim só dos governantes, é o Prefeito que tem que vir aqui, é o Governo que tem que dar essa assistência, e vai indo. Olha, a gente tenta às vezes adaptar a realidade por que assim em relação o que mais incomoda a gente aqui é essa questão da água. Âs vezes a gente traz água de Jequitinhonha, água tratada, mas aí se acaba, ce toma água tratada mas toma banho, lava roupa na água contaminada (e10).

Principalmente sobre saúde, a água, que a gente tem que ter uma água boa. É, toda vez que entra um novo Prefeito fala aquela conversa bonita que vai fazer é um tratamento de água para os moradores do Caju. Infelizmente a gente, até hoje, nunca alcançou essa boa vontade do Prefeito (e7).
É que de fato a herança contratual, deixada pela modernidade, ainda tem seu lugar. Espera-se ainda que apesar de ser um lugar pequeno, aquelas promessas políticas que ocorrem nas campanhas venham a se concretizar. Assim, sobrevive-se no dia a dia com as condições precárias que se apresentam e sobrevive-se apesar delas.

Eu penso tanta coisa, mas eu acho que o melhor que a gente tem que pensar é pedirpara tratar da água, porque senãa esse tratamento que a gente fa z vira engano. Principalmente para esquistossomose. E depois pra muitas coisas, porque aqui tem muitas coisas, além do tratamento da água (e1).

Mas agora temos tratamento de esquistossomose, vem o tratamento e depois vem a preocupação: E a água? Como fica a situação da água? Eu acho que é uma coisa assim que os administradores deveriam estar agilizando o quanto antes por que nós tomamos o remédio da esquistossomose no ano passado, nós estamos em maio de 2005... A água continua a mesma... Igual há cinco anos atrás o pessoal da FUNAS A [Fundação Nacional de Saúde] fez um tratamento da esquistossomose aqui. Ai chegon esse projeto agora e nos exames deu mais de $70 \%$ com esquistossomose. Um círculo vicioso... (e6).

[...] Que a gente espera que eles cuidem dessa água por que se a gente não tiver uma água tratada a gente não vai ter uma boa saúde. A gente trata todo ano, vai ao médico, faz um check-up, faz uns exames completos, dá positivo, trata, mas volta para o lugar, continua mexendo com aquela água... mas é aquela mesma água, não é tratada, ela está contaminada... e a gente adoece de novo... (e7).

Portanto, é essa a realidade que se apresenta. Geralmente as atividades educativas para a promoção da saúde com a finalidade de evitar a contaminação da doença, semprepropõem mudança de comportamento aos habitantes do lugar. Como nem sempre mudam, reafirma-se o discurso que "culpabiliza a vítima", que reduz "[...] o âmbito do problema ao nível do indivíduo e sua extensão ao nível do comportamento. Desta maneira não fariam parte da promoção da saúde os fatores e condições que estivessem fora do controle dos próprios indivíduos". ${ }^{13: 84}$ Pois as discussões sobre a doença ao se ampliarem coloca em evidência a constante necessidade de saneamento básico, com abastecimento de água, medidas que já se comprovaram mais do que eficientes contra a contaminação ou suas recidivas.

Assim, vai se vivendo o cotidiano dentro das possibilidades que se apresentam mesmo que precárias e impossíveis de se imaginar. "A saturação da política que é, por essência, distante, projetiva, restitui toda a importância ao cotidiano e às relações de 'proxemia'. Ao que estaria por vir, isto que seria unicamente espera- 
do em um quadro futuro de uma sociedade perfeita, ou por fazer, tornou-se visível, possível e mesmo palpável. Isto é o que eu chamo de transfiguração da política. Esta deixoulugar aodoméstico, comaculturadosentimento que é sua expressão mais visível". 5:61

Pois, a vida cotidiana é feita de razão e emoção, realidadeesonho, sentimentoscompartilhados, noestar junto, na relação no e como espaço vivido, construindoodiariamente. "Então que o mundo empírico comporta estabilidade e regularidade, o mundo imaginário está proliferando, transgredindo as pressões do espaço e do tempo. A essência do sonho vai se misturar com aquela da realidade, sem que o ser humano tenha consciência. De onde as ilusões loucas, as miragens quase alucinatórias, a perseguição de quimeras. A importância do imaginário abre o caminho aos delírios do bomo demens, mas assim à fantástica inventividade e criatividade do espírito humano[...]. Assim este sonhou tanto em voar que os aviões nasceram [...]. Da mesma maneira que se tem necessidade de afetividade, a realidade tem necessidade do imaginário para ter consistência. Nosso mundo real é nesse sentido meio imaginário". ${ }^{14: 122}$

Assim, os moradores de Caju sonham e imaginam uma realidade possível, mais solidária, com sentimentos e desejos compartilhados, em busca de uma saúde também possível.

Se eu for ficar pensando: - eu tenho que sair daqui porque aqui tem esquistossomose, isso vai ser ruim. Eu tenho que pensar assim: - eu tenho que procurar mudar.. tentar mudar a maneira das pessoas pensarem - aqui não presta porque tem esquistossomose. Não, aqui pode melhorar [...]. Ai, eu acho que depende muito de nós mesmos. Porque se a gente ficar só esperando que Prefeito tem que fazer, que isso e aquilo, nunca vai acontecer. Acho que a gente mesmo deve começar a buscar a melhoria para gente. Igual tem muita gente ai que pega o lixo e joga dentro do córrego, isso ai não é bom! Pega e queima. Tem tanta coisa melhor para fazer. Porque que joga dentro do córrego para poluir a água? Eu acho que essa melhoria tem de vir primeiramente de nós mesmos (e9).

[...] quando o pessoal mostrou para gente como é que é a água que a gente toma então isso a gente movimenta começa a fazer abaixo-assinado com o povo para poder tentar pedir a Prefeitura para poder estar mandando água pra cá (e10).

Constata-se, portanto, o viver cotidiano que se estabelece nesse espaço, mesmo que em condições precárias. A vida dessas pessoas é vivida da forma que elas concebem, apesar das contradições que possam ser observadas, há um latente vitalismo, que faz com que prossigam em busca de uma melhoria da qualidade de vida do lugar e consequentemente de si próprios.
Observa-se que "[...] rebeliões, revoltas, indiferenças políticas, importância da proxemia, valorização do território, sensibilidade ecológica, retorno as tradições culturais e recorrer às medicinas naturais, tudo isto, $\mathrm{e}$ poder-se-ia por lazer prosseguir a lista, traduz a continuidade, a tenacidade de um valer-viver, individual e coletivo, que não erradicou-se totalmente. É a expressão de uma irrepreensível saúde popular. A emergência de uma tática existencial alternativa. Um exercício de reconciliação de qualquer sorte. Reconciliação com os outros e com o mundo que se partilha entre si". 9:39

Possivelmente, a busca de um re-encantamento do mundo e da vida, que como o rio, segue seu curso até desaguar no oceano, sem retornar à sua nascente, essas pessoas vão seguindo seu rumo, construindo sua história, seu processo de viver. A história de um lugar que se torna a própria história de cada um.

\section{NO CURSO DO RIO}

Na tentativa de finalizar o presente trabalho algumas reflexões se fazem necessárias. Apesar das condições pouco favoráveis que se mostram ao olhar intelectual ou profissional ou mesmo urbano, revela-se nos moradores de Caju, um vitalismo latente de viver a vida.

É necessário muitas vezes conter o afã profissional de tudo resolver, "dar" condições para que as pessoas vivam melhores, pois muitas vezes, essa forma não condiz com os desejos dessas pessoas. Geralmente os programas oficiais de atenção à saúde e de educação tem como objetivos "conscientizar" ou sensibilizá-las para que tenham uma mudança de comportamento, a fim de obterem melhores condições de vida. Porém, depois de conviver com elas, questiono-me de que forma isso poderia acontecer?

A questão que se impõe é que, "não se trata de 'despertar' ou 'sensibilizar' a população, como pretendem os programas oficiais de educação em saúde e muitos outros. Trata-se de valorizar aquilo que os sujeitos têm de melhor, sua história, seu tempo - a sua capacidade de criação". 15:240

Destaforma, buscar compreender esse vitalismo que é inerente ao ser humano, percebendo a estética desta vida cotidiana, que vai moldando histórias de cada um, histórias de um lugar, a relação com espaço onde se vive a vida de cada dia. Sob um olhar mais sensível é constatar "adesão aos outros, em função dos gostos, das origens, dos sonhos e das histórias ou mitos comuns. Adesão a um território, a uma natureza, a uma paisagem partilhada. Socialidade de base, comportando uma boa parte do inconsciente 
não dito, certamente, ou do imaginário reivindicado. Outra maneira de dizer este valer-viver obstinado que faz que, apesar das crises, das mudanças de valores, sem falar das peripécias políticas, ou econômicas, em resumo, de uma maneira misteriosa a vida perdura $\mathrm{e}$ se acomoda em suas diversas vicissitudes". 9:31

Socialidade que se apresenta nas relações cotidianas que os sujeitos estabelecem entre si e com o espaço onde habitam. Mesmo que cercados por adversidades, eles acreditam, criam, sonham e realizam possibilidades de serem saudáveis. Possibilidades da ordem do vitalismo. Essa potênciainerente ao homem, queéencontrada na vontade, no desejo, na permanência de viver, permeada pelo sentimento, pela emoção, pelo afeto, que não se explica pela razão. É esse vitalismo, que dá sentidoà luta diária pela sobrevivência, nesta vida considerada sem qualidade. Que, “apesar de”, lhes permite enfrentar as adversidades, manter o instinto de preservação, dá-lhes o riso, a alegria, o sonho. Algo que fica na ordem do inexplicável, mas que se compreende na "necessidade de uma centralidade subterrânea". 16:20

Essa centralidade subterrânea que não é única, mas que são múltiplas e que se encontram além da história oficial ou do que ocorre nas relações sociais. Ela constrói infinitas histórias no cotidiano da existência dessas pessoas. Essas minúsculas formas de interação que dão força ao vitalismo inerente ao homem, traduzidas nas ações cotidianas, no compartilhamento dos "pequenos nadas" com outros, na inserção em seu espaço.Éo estarjunto, à toa ou não, vivenciando instantes, que são importantes pela sua própria efemeridade. É o experimentar em comum, trocar, ter significados próprios, vivenciar sentimentos, sejam eles quaisforem, pois a socialidade não évivida, apenas, harmoniosamente, pelo contrário, ela é da ordem do diferente e por isso compartilhada em uma "harmonia conflitual". ${ }^{16}$

Essa socialidade, que tira do anonimato as pessoas do lugar, é vivida com intensidade, o que muitas vezes, pode ser incompreensível para os de fora. Esse lugar que é daqueles que ali vivem. "Ele é mesmo do re-investimento do espaço. Da valorização de todos esses 'pedaços' de terra que são os produtos do terreno, os pratos regionais, a importância do quarteirão, ou do país, mesmo que seja um pequeno canto do mundo onde se vive, o ressurgimento das línguas locais e dos rituais cotidianos aos quais estão ligados. Tudo isto que constitui o prazer corporal. Estes são todos os fenômenos que, em sua própria banalidade estruturam o corpo. Por ai se exprime um imaginário social se 'espacializando', se encarnando. Causa e efeito do sentimento de pertencimento". 9:70
Esse sentimento de pertencimento possibilita uma estética do ser saudável, moldada em movimentos peculiares, que mostra a interação com o espaço, construindo e sendo construída. Estética que se apresenta de formas variadas, captada de maneira sutil, nas mais variadas nuanças, entendida em seu sentido etimológico, "[...] no sentido de vivenciar ou sentir em comum". 16:15 Expressas nas ações diárias realizadas, na existência comum da vida cotidiana, com a força da interação que possuem entre si e com o espaço que circunscreve esta existência. Uma existência um tanto precária, difícil, dura, uma realidade cruel, mas nem mesmo por isso vazia de significados e sonhos. Se a vida desse lugar pode ser considerada por muitos como banal, vive-se uma existência comum- uma existência em comunhão - vive-se o aqui e agora, o presente. Ali, independente de como a vida se apresenta, há esse sentimento de pertencimento quelhes confere uma identificação, que não espelha no dever-ser e sim, no estar-junto.

É nesse lugar, contraditório, mas suavizado pela carga simbólica, que eles moram com toda a complexidade. Moram no sentido de pertencer a umlugar.Interagem com as adversidades, mas sabem buscar a forma de como sobreviver. Ali, onde a vida se apresenta precária, vive-se o presente, porque pelo pouco que se tem não se pode projetar um futuro, buscar melhorias para o amanhã, como pregao mundoprometeíco, progressista. Se há um ajustamento desta existência em comum, ela tem um lugar, que dá espaço para esta ligação social, pontilhadas e abaladas por sobressaltos violentos, caóticos, imprevisíveis, mas que testemunham uma sólida organicidade, que traduzem o ser saudável.

Talvez, seja complicado pensar que nesse lugar onde vivem, são saudáveis, mas pode ser possível. Pois a dura realidade, com as condições precárias e adversas apresentadas, ao ser mesclada com o imaginário, com o sonho desses moradores, resulta em possibilidades de serem saudáveis. Podem viver em condições precárias, mas estão inseridos em um espaço-tempo, ao qual pertencem, no qual constroem suas existências, subjetivas e singulares. E tal constatação deveria começar a fazer parte daquilo que, enquanto profissionais de saúde, consideramos como cuidado, pois o processo de viver humano não se estabelece apenas sobre bases objetivas.

\section{REFERÊNCIAS}

1 Santos M. Expedição Jequitinhonha relatório. Belo Horizonte (MG): Assembléia Legislativa do Estado de Minas Gerais. 2004 [acesso 2006 Mar 03]. Disponível em: http//:www.almg.gov.br/bancoconhecimento/ monografia/relatório\%20jequitinhonha.pdf 
2 Gonçalves RN. Diagnóstico ambiental da Bacia do Rio de Jequitinhonha. Salvador (BA)/Brasília (DF): Ministério do Planejamento e Orçamento, IBGE, Diretoria de Geociências, Divisão Geociências NE. 1997 [acesso 2006 Mar 03]. Disponível em: http//:www.ibge. gov.br/home/geociências

3 Maffesoli M. Au creux des apparences: pour une éthique de l'esthétique. Paris (FR): Plon; 1990.

4 DuvignaudJ.Lieux et non lieux. Paris(FR): Galilée; 1977.

5 MaffesoliM.Lacontemplation du monde: figuresdustyle communautaire. Paris (FR): Bernard Grasset; 1993.

6 Weber M. Essais sur la theórie de la science. Paris(FR): Presses Pocket; 1992.

7 Yin RK. Estudo de caso: planejamento e métodos. 2a ed. Porto Alegre (RS): Bookman; 2001.

8 Foucault M. Philosophie: anthologie. Paris (FR): Gallimard; 2004.

9 MaffesoliM.Lêrythmedelavie:variationssurlessensibilités postmodernes. Paris (FR): La table ronde; 2004.
10 Bachelard G. L'eau et les rêves: essai sur l'imagination de la matière. Paris (FR): Librarie José Corti; 2005.

11 Word Water Council, Comisión Nacional del Agua. $4^{\text {th }}$ Word Water Forum [acesso 2006 Ago 07]. Disponível em: http://www.worldwaterforum4.org.mx/home/home.asp

12 Moraes DSL, Jordão BQ.Degradaçãode recursos hídricos e seus efeitos sobre a saúde humana. Rev Saúde Públ. 2002 Jun; 36 (3): 370-4.

13 Verdi M, Caponi S. Reflexões sobre a promoção da saúde numa perspectivabioética. Texto ContextoEnferm. 2005 Jan-Mar; 14 (1): 82-8.

14 Morin E. La méthode: l'identité humaine. Paris (FR): Seuil; 2001.

15 Oliveira RM. A dengue no Rio de Janeiro: repensando a participação popular. Cad Saúde Públ. 1998; 14 (supl.2): 69-78.

16 Maffesoli M. O tempo das tribos: o declínio do individualismo nas sociedades de massa. Rio de Janeiro (RJ): Forense-Universitária; 1987. 